\title{
Health Information Seeking and Social Media Use on the Internet among People with Diabetes
}

\author{
Ryan J Shaw ${ }^{1}$, Constance M Johnson ${ }^{1}$ \\ ${ }^{1}$ Duke University School of Nursing, Durham, NC
}

\begin{abstract}
Patients who are active and involved in their self-management and care are more likely to manage chronic conditions effectively $(6,26)$. With a 5-fold increase in the incidence of chronic illness over the past 20 years, access to information can provide patients the tools and support to self-manage their chronic illness. New media technologies can serve as tools to engage and involve patients in their health care. Due to the increasing ubiquity of the Internet and the availability of health information, patients are more easily able to seek and find information about their health.. Thus, the Internet can serve as a mechanism of empowerment $(4,5)$. This is especially important for people with diabetes mellitus where intensive selfmanagement is critical.
\end{abstract}

\section{Introduction}

Diabetes is the sixth leading cause of death in the US (31). Over 24 million people in the US have diabetes, with over 1.6 million new cases diagnosed in 2007 in people over the age of 20 (29). In particular, minorities are disproportionately affected by diabetes. African American and Native American adults are twice more likely to have diabetes than white adults (33). If this trend continues, one third of all Americans will develop diabetes and will lose an average of 1015 years of life (29). The most common form of diabetes is type 2, which is linked to obesity and physical inactivity, and accounts for $90 \%-95 \%$ of diabetes cases (29).

Diabetes causes serious complications and can lead to poor quality of life (1). People with diabetes are more susceptible to other illnesses and often have a worse prognosis from them. Yet, people with diabetes can reduce the occurrence of these potential complications through lifestyle management.

There are many secondary prevention (glucose control and blood pressure control) and tertiary prevention (screening for eye, foot and kidney abnormalities) measures available to prevent the onset of diabetes and decrease the severity of diabetes complications (12). Strategies that would decrease the burden of diabetes are not used regularly, resulting in increased morbidity, 
complications and expenses (34). People with diabetes who are compliant with their regimen and maintain strict glycemic control have lower rates of complications (30). Training and education to help people self-manage their diabetes helps prevent unnecessary health care utilization and hospitalization (8). People who have increased morbidity and mortality risk, particularly those with a disability or chronic illness such as diabetes, are more likely to engage intensely with online resources (18).

Searching for health information is the third most popular use of Internet technology (17). It is estimated that in the US, health information is sought online by $81 \%$ of Internet users and $66 \%$ of all adults (22). The Internet brings to the general population the ability to perform in-depth information searches and can assist health consumers with treatment decisions, in determining when to see a provider, and to help prepare them to actively participate in their care (20). Research demonstrated that online social support programs targeting chronic illness have been shown to decrease symptoms, improve health behaviors and reduce utilization of health care resources (28). Through the Internet, online programs can serve as an interactive medium for providing health information and enhancing social support.

Research suggests that health communication is more effective when it reaches people on an emotional as well as a rational level, relates to people's social or 'life' contexts, is a combination of interpersonal communication and mass media, is tailored, and is interactive (32). Online social media such as Facebook, one of many online social networking sites, has these communication elements in its design. Since 2004, it has become increasingly popular with over 350 million users worldwide, and over 100 million users in the U.S. alone (14). More than $25 \%$ of US adults over 50 stay connected using online social networking sites (2010).

Other online social media outlets such as Twitter, YouTube, and blogs are also popular mediums for communication. Twitter is a social networking and micro blogging site that allows users to post and read short messages, "tweets", of up to 140 characters. These messages are posted to the author's website and sent out to subscribers. Twitter has over 175 million users and over 95 million tweets are written per day (37). Users are on average between the ages of 18-55 and are equally male and female (37). YouTube is the world's most popular online video community and allows users to share original-created videos. There are over 3 million YouTube subscribers and over 2 billion videos a day are watched (39). Over 100 million blogs are estimated to exist with the average user being between 21-35 years old with an equal balance of males and females (36).

Popular online social media sites are platforms that can potentially be used to reach out to large numbers of people to deliver health education and support. However, evidence of how popular online social media and networking sites (i.e. Facebook, Myspace, Habbo, Twitter, YouTube, etc.) can be used as a milieu for delivering chronic illness education and support is lacking. In addition, we do not know how well we can leverage these mediums to reach minority populations where diabetes in particular is especially prevalent. By understanding the online health-seeking behaviors of people with diabetes and their use of online social media, in particular online social networking, we may be able to understand how to reach people to deliver diabetes education and promote social support through these new media.

The purpose of this study was to examine the online health-seeking behaviors of people with a chronic illness. The researchers asked the following questions: (1) what are the online social 
media use behaviors of people with diabetes? (2) Are people with diabetes willing to use online social media to discuss their health status and health information? (3) Are these mediums appropriate for reaching minority and rural populations?

\section{Methods}

\section{Design and Sample}

This study used a cross-sectional survey design with a convenience sample of people with diabetes $(n=57)$ recruited from the sub-urban and rural Southeastern, US between June and October 2009. Flyers were placed in primary care clinics and libraries across two counties. Participants were asked to complete an online web-based survey tool (SurveyMonkey.com LLC, Palo Alto, CA). Due to the length of the web address URL, a shortened URL was created through TinyURL.com and placed on the flyers and online classified ads.

Flyers were posted on bulletin boards near computer stations to help maximize recruitment. Flyers were reposted each month to replenish tear off tags and to comply with the 30 day flyer limit at many locations. In addition, on two separate occasions, an online classified advertisement was placed on a free online local classified service. Participants who responded to the online advertisement clicked a link that sent them directly to the online survey. Eligibility criteria were aged 21 and over, diagnosis of Type 2 diabetes, able to read and write in English, and able to give consent. At the end of the survey, participants entered their name and mailing address to receive a $\$ 10$ compensation for completing the survey. The Duke University Medical Center IRB approved the study protocol.

\section{Measures}

Participants met the inclusion criteria by completing a demographic survey that determined eligibility and proceeded to the second section of the survey. The second part of the survey asked for information about participants' diabetes, and their Internet and online social networking use. Questions related to Internet use, types of health information sought online, and online health seeking behaviors were adapted (23). The author developed specific questions about online social networking, YouTube, and Twitter use. These questions asked about frequency of use and willingness to use these venues to discuss health information.

\section{Analytic Strategy}

Descriptive statistics and correlation analyses were using JMP (SAS inc. Cary, NC) were employed to describe the sample, to determine access to health information online, willingness to discuss health information online, use of online social media and their correlations by race.

\section{Results}

Fifty-seven participants completed the online questionnaire. The majority of the sample was female $(75.4 \%)$ with nearly half identifying as White non-Hispanic; the respondents reported membership in a wide range of race/ethnic groups (see Table 1). Participants were highly educated and the majority had used the Internet for 4 years or more. The mean time of diagnosis with diabetes was 7 years. 
The majority of participants used the Internet to search for health information (see Table 2). There was a non-significant correlation between searching health information online and race (df $=1, \mathrm{r}=.2, \mathrm{p}>.1)$. This indicates that health information seeking online was sought equally among participants regardless of race. Of the participants $(n=8)$ who do not seek health information online, half $(n=4)$ indicated they are not comfortable seeking health information online. Among the participants that seek health information online, $36(78.5 \%)$ indicated that the health information they found online has changed the way they think about health. A variety of diabetes-related information is sought online. Many participants reported using popular online social networking sites such as MySpace or Facebook, accessing them frequently two or more times per week. There was a non-significant correlation between using a popular online social networking site and race $(\mathrm{df}=1, \mathrm{r}=-.13, \mathrm{p}>.1)$. This indicates that popular online social networking sites were used regardless of race. The majority of participants read online blogs. Approximately half of participants watched YouTube and only a few used Twitter. Many participants would be willing to discuss health information online in chat rooms, discussion groups, or online support groups (see Table 3). There was a non-significant correlation between willing to discuss health information online and being a person of color $(\mathrm{df}=1, \mathrm{r}=-.1, \mathrm{p}>.1)$. This indicates that people were willing to discuss health information online regardless of race.

Table 1. Demographics $(n=57)$

\begin{tabular}{|c|c|}
\hline Female & $43(75.4 \%)$ \\
\hline \multicolumn{2}{|l|}{ Race/Ethnicity } \\
\hline White non-Hispanic & $28(48.3 \%)$ \\
\hline African American & $23(39.7 \%)$ \\
\hline Hispanic & $2(3.4 \%)$ \\
\hline Asian-Pacific Islander & $3(5.2 \%)$ \\
\hline Native American & $4(6.9 \%)$ \\
\hline Other & $1(1.7 \%)$ \\
\hline \multicolumn{2}{|l|}{ Education } \\
\hline Less then high school & $3(5.2 \%)$ \\
\hline High school/GED & $4(6.9 \%)$ \\
\hline Some college & $13(22.4 \%)$ \\
\hline Associates & $15(25.9 \%)$ \\
\hline Bachelors & $15(25.9 \%)$ \\
\hline Masters & $7(12.1 \%)$ \\
\hline Doctoral/Professional & $1(1.7 \%)$ \\
\hline \multicolumn{2}{|l|}{ Length of Internet use } \\
\hline$<6$ months & $2(3.5 \%)$ \\
\hline 6-12 months & $1(1.8 \%)$ \\
\hline $1-3$ years & $6(10.5 \%)$ \\
\hline 4-6 years & $12(21.1 \%)$ \\
\hline $6-10$ years & $15(26.3 \%)$ \\
\hline$>10$ years & $21(36.8 \%)$ \\
\hline
\end{tabular}

Table 2. Health information sought online 


\begin{tabular}{|c|c|}
\hline Health information sought online $(\mathrm{n}=57)$ & \\
\hline All participants & $86 \%$ \\
\hline White non-Hispanic & $92 \%$ \\
\hline African American & $78 \%$ \\
\hline Native American & $100 \%$ \\
\hline Information about diabetes is sought online & $82.1 \%$ \\
\hline Diabetes information obtained from the Internet & \\
\hline General information & $69.9 \%$ \\
\hline Treatment options & $60.9 \%$ \\
\hline Ways to cope & $54.3 \%$ \\
\hline Alternative or complementary therapies & $28.3 \%$ \\
\hline Nutrition & $69.9 \%$ \\
\hline Journal articles & $23.9 \%$ \\
\hline Chat rooms, discussion groups, or online & $19.6 \%$ \\
\hline support groups & $19.6 \%$ \\
\hline Financial assistance & \\
\hline
\end{tabular}

Table 3. Online social media

\begin{tabular}{|l|l|}
\hline \begin{tabular}{|l|} 
Created a profile online that others can see (i.e. MySpace, \\
Facebook, or LinkedIn.com)
\end{tabular} \\
\hline All participants & $59.6 \%$ \\
\hline White (non-Hispanic) & $52 \%$ \\
\hline African American & $67 \%$ \\
\hline Native American & $100 \%$ \\
\hline Frequency of visiting online social networking sites \\
\hline Daily & $41.9 \%$ \\
\hline Almost daily & $11.6 \%$ \\
\hline 5-6 time per week & $4.7 \%$ \\
\hline 2-4 times per week & $16.3 \%$ \\
\hline 1 or less times per week & $25.6 \%$ \\
\hline Frequency of reading online blogs & $15.7 \%$ \\
\hline Daily & $5.9 \%$ \\
\hline Almost daily & $3.9 \%$ \\
\hline 5-6 time per week & $11.8 \%$ \\
\hline 2-4 times per week & $27.5 \%$ \\
\hline 1 or less times per week & \\
\hline Frequency of watching YouTube & $13.7 \%$ \\
\hline Daily & $3.9 \%$ \\
\hline Almost daily & $3.9 \%$ \\
\hline 5-6 time per week & $29.4 \%$ \\
\hline 2-4 times per week & $23.5 \%$ \\
\hline 1 or less times per week & $25.5 \%$ \\
\hline Never & \\
\hline
\end{tabular}




\begin{tabular}{|l|l|}
\hline Frequency of Twitter use & \\
\hline Daily & $2 \%$ \\
\hline Almost daily & $2 \%$ \\
\hline 5-6 time per week & $2 \%$ \\
\hline 2-4 times per week & $2 \%$ \\
\hline 1 or less times per week & $9.8 \%$ \\
\hline Never & $82.4 \%$ \\
\hline $\begin{array}{l}\text { Used an online patient portal to access medical records and } \\
\text { health information }\end{array}$ & $19.2 \%$ \\
\hline $\begin{array}{l}\text { Willing to discuss health information online in chat rooms, } \\
\text { discussion groups or online support groups }\end{array}$ & \\
\hline All participants & $65.4 \%$ \\
\hline White (non-Hispanic) & $60 \%$ \\
\hline African American & $67 \%$ \\
\hline Native American & $100 \%$ \\
\hline
\end{tabular}

\section{Discussion}

These results suggest that a significant percentage of people with diabetes seek health information online and in particular information about diabetes. This is consistent with the literature that states that over $61 \%$ of American adults seek health information online (19). The majority of participants from this study frequent popular online social networking sites (i.e., Facebook, Myspace, etc.) and would be willing to discuss health information on these venues. Approximately half of the survey respondents were non-White with no significant difference between race in searching for health information online, utilizing popular online social networks, and willingness to discuss health information online. In addition, participants were recruited from a rural and suburban location in the Southeastern, US. This may indicate that using these online venues could reach diverse and non-urban populations. These results compliment findings that people with diabetes use online resources and diabetes specific online social networks such as DiabetesFriends.net with over 1,000 members (13) and TuDiabetes.org with over 16,000 members (11). Other online social networking sites include Dlife (27), DiabetesSisters (2), and the DiabetesOC (7). A search on Facebook revealed over 500 existing diabetes related groups such as The Heart of Diabetes (15) and Talk Diabetes (16).

Web-based venues can be beneficial in promoting positive health behavior change (38) and serve as a setting to deliver and improve diabetes social support $(3,35)$. Our results suggest that online social media, and in particular popular online social network sites (i.e., Facebook, Myspace, etc.), may be an appropriate way to reach people to deliver diabetes education and to implement social support networking. Though diabetes specific online social networking sites already exist, they do not contain the immense number of subscribers, as do the mainstream popular online social networking sites such as Facebook.

\section{Limitations}


The limitations of this pilot study are that this study only represents participants from one urban setting in the Southeastern US and is not representative of the US general population. This study has a small sample size. Recruiting from the online classified service Craig's List may have skewed the sample to more computer literate participants.

Implications for Future Research

Further research is needed to understand how we can make use of these popular online social networking sites to reach people directly where they are and utilize features of these sites for delivering diabetes education and support. Specifically further investigation of how to engage people to join diabetes social networks within popular online social networks.

There are many features of these sites that may serve as valuable tools for communication for social support and education. These communication tools include private or public messages, instant chat features, news feeds, blogging, fan groups, and video and photo sharing. In particular, these sites are imbedded with applications that can potentially deliver and generate tailored health information and outreach to people through analysis of information on individuals' social networking page. As a pedagogical platform, interactive applications can be created that deliver diabetes and social support education. These can exist in forms such as surveys, tests or games. Needed are randomized controlled interventions that evaluate the mechanisms of these sites, their impact on physiological and psychological diabetes outcomes, and how nurses can be integrated to serve as deliverers or moderators of care.

Additionally, researchers must carefully take into account the issues of privacy and security with regard to health information and consider the implications of the HIPAA privacy rule on social networking websites. Consideration to protect people's health information and how to prevent a false sense of privacy is needed (21).

\section{Conclusion}

Social networks can impact behavior change (10). Health improvements in one person may spread to another (Christakis \& Fowler, 2008), through a "viral" process. Popular online social networks may have a similar impact and have been shown to change perceptions of social support (3). With the advent of Web 2.0, Internet users are now able to dynamically communicate with each other through video, wikis, blogs, virtual environments, and social networking technologies. These in many ways allow similar social networking behaviors to exist online as they do in real life with the added advantage of being able to easily connect to anyone in the world. By integrating aspects of the health care delivery system into these venues, health care providers may be able to help people become increasingly involved in their care leading to informed and activated patients. This in turn could potentially lead to improved health outcomes. With over 100 million active users in the US on Facebook alone (14),popular online social networks and online social media have the potential to serve as important platforms for nursing and public health interventions and to reach diverse populations (24).

\section{References}


1. American Diabetes Association. Type 2 Diabetes Complications. Retrieved May 11, 2009, from http://www.diabetes.org/type-2-diabetes/complications.jsp

2. Barnes B. Diabetes Sisters. Retrieved June 25, 2010, from, www.diabetessisters.org

3. Barrera M, Jr, Glasgow RE, McKay HG, Boles SM, Feil EG. 2002. Do Internet-based support interventions change perceptions of social support?: An experimental trial of approaches for supporting diabetes self-management. Am J Community Psychol. 30(5), 637-54. http:// dx.doi.org/10.1023/A:1016369114780

4. Bergman DA, Brown NL, Wilson S. 2008. Teen use of a patient portal: a qualitative study of parent and teen attitudes. Perspect Health Inf Manag. 5, 13.

5. Broom A. 2005. Virtually He@lthy: The impact of Internet use on disease experience and the doctor-patient relationship. Qual Health Res. 15, 325-44. http://

dx.doi.org/10.1177/1049732304272916

6. Bull SS, Gaglio B, McKay HG, Glasgow RE. 2005. Harnessing the potential of the internet to promote chronic illness self-management: diabetes as an example of how well we are doing. Chronic Illn. 1(2), 143-55. http://dx.doi.org/10.1177/17423953050010021101

7. Capone G. The Diabetes OC. Retrieved June 25, 2010, from www.thediabetesoc.com/ 8. Centers for Disease Control. (2008). Preventing chronic diseases: investing wisely in health. Preventing diabetes and its complications.

9. Centers for Medicare \& Medicaide Services. (2009). Diabetes self-management. Retrieved May 11, 2009, from www.cms.hhs.gov/DiabetesSelfManagement/

10. Christakis NA, Fowler JH. 2008. The collective dynamics of smoking in a large social network. N Engl J Med. 358(21), 2249-58. http://dx.doi.org/10.1056/NEJMsa0706154

11. Diabetes Hands Foundation. TuDiabetes. Retrieved June 2, 2010, from tudiabetes.org 12. Diabetes Prevention Program Research Group. 2002. The diabetes prevention program (DPP): Description of lifestyle intervention. Diabetes Care. 25, 2165-71. http:// dx.doi.org/10.2337/diacare.25.12.2165

13. DiabetesFriends.net. (2010). Network Statistics. Retrieved September 30, 2010, from www.diabetesfriends.net/home.php

14. Eldon E. (2009). Facebook reaches over 100 million active users in the United States. from www.insidefacebook.com/2009/12/07/facebook-reaches-100-million-monthly-active-users-inthe-united-states/

15. Facebook. (2010a). The Heart of Diabetes. Retrieved June 25, 2010, from www.facebook.com/heartofdiabetes

16. Facebook. (2010b). Talk Diabetes. Retrieved June 25, 2010, from www.facebook.com/ group.php?gid=47761983106

17. Fox S. (2003). Internet health resources: Health searches and email have become more commonplace, but there is room for improvement in searches and overall Internet. Pew Internet \& American Life Project.

18. Fox S. (2008). The engaged e-patient population. Pew Internet \& American Life Project. www.harrisinteractive.com/harris poll/index.asp?PID $=937$

19. Fox S, Jones S. (2009). The social life of health information: Americans' pursuit of health takes place within a widening network of both online and offline sources. Washington, DC: Pew Internet \& American Life Project.

20. Fox S, Rainie L. (2000). The online health care revolution: How the Web helps Americans take better care of themselves Online life report. Washington, DC: Pew Internet \& American Life Project. 
21. Graham LK. 2009. What is social networking? And how do I get clued in to LinkedIn? J Am Diet Assoc. 109(1), 184.http://dx.doi.org/10.1016/j.jada.2008.11.016

22. HarrisInteractive. (2008). Number of "cyberchondriacs" - adults going online health information - has plateaued or declined. Retrieved July 16, 2009, from www.harrisinteractive.com/ harris poll/index.asp?PID=937

23. Helft PR, Eckles RE, Johnson-Calley CS, Daugherty CK. 2005. Use of the Internet to obtain cancer information among cancer patients at an urban county hospital. J Clin Oncol. 23(22). http:// dx.doi.org/10.1200/JCO.2005.09.621

24. Khan AS, Fleischauer A, Casani J, Groseclose SL. 2010. The next public health revolution: public health information fusion and social networks. Am J Public Health. 100(7), 1237-42. http:// dx.doi.org/10.2105/AJPH.2009.180489

25. Koppen J. (2010). Social Media and Technology Use Among Adults 50+. Washington DC: AARP.

26. Levelle SG, Huang A, Tsai SB, Weingart SN, Lezzoni LI. 2008. Screening for chronic conditions using a patient Internet portal: Recruitment for an Internet-based primary care intervention. J Gen Intern Med. 23(4), 472-75. http://dx.doi.org/10.1007/s11606-007-0443-6 27. LifeMed Media. dLife. Retrieved June 2, 2010, from http://diabetescommunity.dlife.com 28. Lorig KR, Ritter PL, Dost A, Plant K, Laurent DD, et al. 2008. The Expert Patients Programme online, a 1-year study of an Internet-based self-management programme for people with long-term conditions. Chronic Illn. 4(4), 247-56. http://dx.doi.org/10.1177/1742395308098886 29. National Center for Chronic Disease Prevention and Health Promotion. (2009). Diabetes successes and opportunities for population-based prevention and control. Atlanta, GA: Centers for Disease Control and Prevention.

30. National Diabetes Information Clearinghouse. (2008). The Diabetes Control and Complications Trial and Follow-up Study. Retrieved May 7, 2009, from http:// diabetes.niddk.nih.gov/dm/pubs/control/

31. National Institute of Diabetes and Digestive and Kidney Diseases. (2008). National diabetes statistics, 2007 fact sheet. Bethesda, MD: U.S. Department of Health and Human Services, National Institutes of Health.

32. Neuhauser L, Kreps GL. 2003. Rethinking communication in the E-health era. J Health Psychol. 8(1), 7-23. http://dx.doi.org/10.1177/1359105303008001426

33. Office of Minority Health. (2010). Diabetes data/statistics. Retrieved Februrary 2011 from, http://minorityhealth.hhs.gov/templates/browse.aspx?lvl=3\&lvlid=62

34. Office of Disease Prevention and Health Promotion. (2000). Healthy People 2010: Diabetes: Centers for Disease Control and Prevention.

35. Smith L, Weinert C. 2000. Telecommunication support for rural women with diabetes.

Diabetes Educ. 26(4), 645-55. http://dx.doi.org/10.1177/014572170002600412

36. Sysomos Inc. (2010). Inside Blog Demographics. Retrieved August 10, 2010, from www.sysomos.com/reports/bloggers/

37. Twitter. (2010). About. A few Twitter facts. Retrieved September 14, 2010, from http:// twitter.com/about

38. Wantland DJ, Portillo CJ, Holzemer WL, Slaughter R, McGhee EM. 2004. The effectiveness of Web-based vs. non-Web-based interventions: a meta-analysis of behavioral change outcomes. J Med Internet Res. 6(4), e40. http://dx.doi.org/10.2196/jmir.6.4.e40

39. YouTube. (2010). YouTube Fact Sheet. Retrieved August 20, 2010, from www.youtube.com/ t/fact sheet 